\title{
Correction to: Electrosynthesis of silver metal nanocomposites in a copolymer matrix of 1-vinyl-1,2,4-triazole and acrylic acid
}

\author{
S. H. Sargsyan ${ }^{1}$ (1) - A. S. Sargsyan ${ }^{2}$ - A. V. Meltonyan ${ }^{3} \cdot$ A. H. Poghosyan ${ }^{3} \cdot$ K. S. Margaryan ${ }^{2}$ \\ Published online: 27 February 2021 \\ (c) The Polymer Society, Taipei 2021
}

\section{Correction to: Journal of Polymer Research (2021) 28:39 https://doi.org/10.1007/s10965-020-02401-0}

Due to an oversight by the Publisher during the typesetting stage, an uncorrected version of the paper was published. The revisions submitted by the author had not been carried out. The paper has now been updated and includes all the author's corrections (listed below):

1. Affiliation 3 should be-NAS RA International Scientific and Educational Center24d Marshal Baghramyan ave0019YerevanArmenia.

2. In Experimental part section, the last line of the last paragraph was deleted.

3. Reference 12 , the page number should be $2126-2129$ and not 126-2129.

The original article can be found online at https://doi.org/10.1007/ s10965-020-02401-0.

\section{S. H. Sargsyan}

artsar86@mail.ru

A. S. Sargsyan

ssargsyan@seua.am

A. V. Meltonyan

info@bioinformatics.am

A. H. Poghosyan

poghosyan@gmail.com

K. S. Margaryan

karinemargaryan55@mail.ru

1 National Polytechnic University of Armenia, St. Teryan 105, 0009 Yerevan, Armenia

2 Yerevan State Medical University After Mkhitar Heratsi, St. Koryun 2, 0025 Yerevan, Armenia

3 NAS RA International Scientific and Educational Center24d Marshal Baghramyan ave0019YerevanArmenia, Yerevan, Armenia
4. Reference 14 should be updated to "Sargsyan SA, Margaryan KS, Sargsyan AS (2018)Russ. J. App. Chem. v. 91. pp 263-266".

5. Reference 25 should be updated to "Pozdnyakov AS, Ivanova AA et al. (2017) Nanocomposites with silver nanoparticles based on copolymer of 1-vinyl-1,2,4-triazole with N-vinylpyrrolidone Russ Chem Bull 66(6): 1099 1103 ".

Publisher's Note Springer Nature remains neutral with regard to jurisdictional claims in published maps and institutional affiliations. 